\section{Spacemen return}

The latest crew of the Soviet Salyut 5 space station have returned safely after an 18-day flight. The programme of the mission was the now-familiar mixture of astrophysical and geophysical observations " in the interests of the national economy", the testing of on-board instruments and systems, and medical observations. The results of one of the medical experiments, which investigated the threshold sensitivity of the vestibular apparatus to electrical stimuli under conditions of weightlessness, will be used to compile criteria for the selection of future cosmonauts.

Japan has meanwhile launched her first geostationary satellite, on 23 February from the Tanegashima Island Space Centre. Although it is Japan's tenth satellite, it is the first to remain in a geostationary orbit and should bring advances in communications and resources surveying.

\section{Change in Grenoble}

Dr John White took over as director of the Institut Laüe-Langevin in Grenoble this week following the departure of Professor Rudolf Mossbauer for a teaching chair at the University of Munich. White's place as assistant director at the Anglo-French-German high flux reactor is taken by Tasso Springer, from the Centre for Nuclear Studies in Julich, West Germany.

\section{EEC geothermal programme}

The European Commission is asking for proposals for research and development for the second stage of its geothermal energy programme. The programme, first announced in August 1975. embraces the acquisition of new geothermal data, prospecting methods. and energy from hot water sources, steam sources and hot dry rocks.

Five UK proposals were accepted for the first stage of the programme, in- cluding one from the CEGB and two from the Natural Environment $\mathrm{Re}$ search (ouncil. The EEC will provide about half the cost of the projects involved.

\section{UK reactor choice}

Sir Alan Cottrell, the UK government's former chief scientific adviser whose questions about the reliability of the steel pressure vessel of the pressurised light water reactor (PWR) prompted a massive study, has again made public his views about the choice of reactor question. In a letter to the Financial Times last week he wrote that Britain "would have little to gain and a lot to lose" by choosing the PWR; he also remained doubtful whether it was right to have to rely for safety on human standards in construction, supervision and operation. He described the merits of SGHWR/Candu and AGR systems as "fairly evenly balanced".
THE most successful and long-running serial put out on the radio by the British Broadcusting Corporation is The Archers, a programme dealing with a farming community in the imaginary village of Ambridge in the midlands of England. Topics of current interest are often introduced: thus Phil Archer, a vigorous and progressive farmer, decides to go on a management course organised by the official Agricultural Training Board. His wife is only being mildly ironical when she says that this will teach him to "avoid friction and frustration with the men, teach a logical approach to human problems, improve their job performance, create teum spirit and good morale, and develop effective face to face communication". The even more successful farmer to whom this was said replies: "It won't leave much time for farming". This episode may appeal to the many scientists who are being pressurised to attend similar courses, organised by the training branches of government departments and research councils. They don't leave much time for research.

Most people would agree that many branches of science are developing so rapidly that it would be casy to get out of date, and that some kinds of 'refresher courses' may be useful. However, good scientists usually manage to keep abreast of their subject. and even find little difficulty in Jealing with the massive literature reporting new work. It has always been the practice in the better institutions for staff to be encouraged to visit other laborutories where advances are being made, and to attend special courses to learn new methods and techniques.

Instruction in such scientific advances is seldom the concern of the training branches which are now becoming so widespread. They are

\section{Man management}

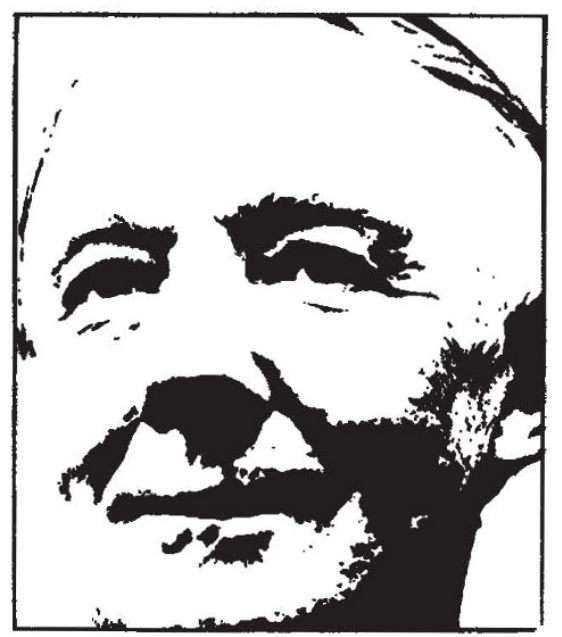

KENNETH MELLANBY

mainly involved in promoting the teaching of 'management'. In this, they have been encouraged by reforms in the scientific civil service following the Fulton Report: changes intended to improve efficiency and promotion prospects. Trades unions have also pressed for this type of course. believing that it may enhance their members' prospects, even if there are doubts as to whether those attending obtain any real benefit.

I have had the opportunity of trying to assess the effects of these management courses on a good many of my colleagues-men and women employed primarily to do research. I have been unable to detect any improvement in their originality or their productivity, or even in their ability to handle their juniors (or their seniors). The courses seem totally useless in promoting scientific research, they waste time which should be spent in the laboratory and they use scarce funds needed for the research itself. I have found this view shared by the directors of many other establishments.

However, the hope is often expressed that, at a suitable stage in their carcers (perhaps when their originality is flagging) more scientists will move to senior administrative posts, and that those who have studied management will then be at an advantage. Has anyone ever carried out a controlled experiment, comparing the performance of the 'trained' and the 'untrained'? I have seen no improvement in those who remain in research. Do these management courses really promote effectiveness in scientific administration-or, for that matter, in business or industry? Until these questions can be answered, we should surely be cautious in encouraging these devclopments. We should certainly not spend moncy intended for research. except perhaps to do the research needed to evaluate the courses themselves. 